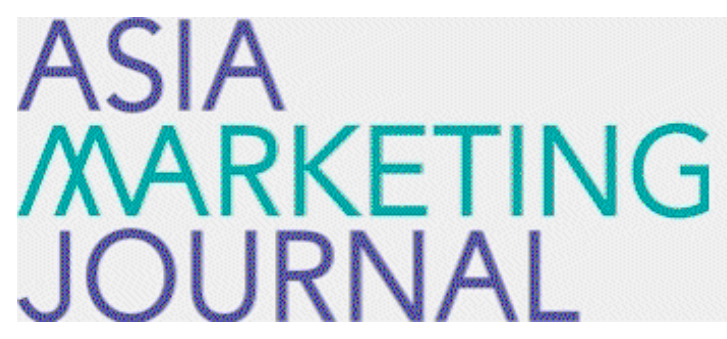

ASIA MARKETING JOURNAL

Volume 21 | Issue 3

Article 1

10-31-2019

\title{
The Effect of Construal Level on Variety Seeking across Subcategories
}

Jiyeon Suh

Eugene J. S. Won

Follow this and additional works at: https://amj.kma.re.kr/journal

Part of the Marketing Commons

\section{Recommended Citation}

Suh, Jiyeon and Won, Eugene J. S. (2019) "The Effect of Construal Level on Variety Seeking across Subcategories," Asia Marketing Journal: Vol. 21 : Iss. 3 , Article 1.

Available at: https://doi.org/10.15830/amj.2019.21.3.1

This Article is brought to you for free and open access by Asia Marketing Journal. It has been accepted for inclusion in Asia Marketing Journal by an authorized editor of Asia Marketing Journal. 


\section{The Effect of Construal Level on Variety Seeking across Subcategories}

Jiyeon Suh*

Eugene J. S. Won**

The present study investigates how consumers' construal level affects their variety seeking behavior when choosing multiple items simultaneously. Especially the authors focus on the perceptual level at which variety seeking takes place and propose that variety seeking can take place not only at brand level but also at category or subcategory level. Categorical variety seeking refers to diversification of one's choices over multiple brands not within the same category but across multiple categories. Building on construal level theory, the authors expected that people engaging in higherlevel construals tend to subcategorize the choice set and distribute their choices across more subcategories and designed four experiments to test the related hypotheses. The experimental results showed that consumers' construal level can affect the level at which variety seeking takes place and those with higher construal level tend to choose options seemingly more dissimilar to each other.

Key words: Variety seeking, Construal level theory, Categorization, Similarity, Simultaneous choices

A large body of studies have focused on choice of a single option, whereas relatively less attention has been devoted to the simultaneous choice of multiple options (Fox et al. 2005). However, quite a few choice situations that consumers face in the real world involve choosing multiple items simultaneously, especially at groceries, restaurants, online bookstores, and online music stores. According to the choice bracketing hypothesis (Read and Loewenstein 1995; Read et al. 1999), having to choose multiple items simultaneously makes individuals assess the consequences of all their choices taken together (i.e., broad bracketing), thereby

* Lecturer, Department of Master of Business Administration, Sejong Cyber University (jiyeonsuh01@gmail.com)

** Professor, Department of Business Administration, Dongduk Women's University (eugene1@dongduk.ac.kr),

Corresponding Author 
all the choices become dependent on one another. Such a tendency leads to more variety seeking in the simultaneous choices condition than in the sequential choices condition (Simonson 1990; Yoon and Suk 2013). The way in which consumers perceptually organize available alternatives affects their choices greatly in such choice situations.

Variety seeking behavior has been one of the most widely studied subjects in marketing (McAlister 1979; Han and Nam 1997). However, most of the previous studies have limited the scope of variety seeking to within-category selection, thus overlooked the possibility of variety seeking occurring at category or subcategory level (Givon 1984; Rosch et al. 1976). The current study suggests that consumers' pursuit of diversity can also be made at category level by distributing their choices across more categories or subcategories. Variability of the level of variety seeking implies one's choice is affected by his or her mental representation of the choice set. This study proposes that consumers' construal level (Trope and Liberman 2003; 2010) can have a serious impact on subdivision of the choice set and variety-seeking behavior across subcategories.

Our hypotheses hold that consumers adopting higher-level construals are more likely to subcategorize the available options and diversify their choices in a way that the number of chosen alternatives from the same sub-group is minimized. Thus, the number of subcategories covered by the chosen alternatives is maximized. Four empirical studies were designed to demonstrate the abstractness of mental representations systematically alters the way one seeks variety. The hypotheses are built upon construal level theory by combining it with the relationship between categorization and similarity perception.

\section{Literature Review and Hypotheses}

Construal level theory(CLT) (Trope and Liberman 2003; 2010) distinguishes between two types of mental representations. Highlevel, abstract construals focus on the central, primary features of the objects and process information inclusively at a superordinate level. In contrast, low-level, concrete construals capture the contextualized specific details, focus on the peripheral, local features, and process information in a piecemeal fashion at a subordinate level. There are several evidences suggesting that people with high-level construal engage in categorization more readily than people with low-level construal (for a review, see Trope et al. 2007).

People who engage in high-level construals tend to see the "big picture" of the situation at hand while their perceptual scope being broader (Bar-Anan et al. 2006; Labroo and Patrick 2009; Liberman et al. 2002; Marguc et al. 
2011). Individuals with high-level construals are likely to simplify choice-related information at the superordinate level whereby categorization is an effective means used for the purpose (Barsalou 1983; Fukukura et al. 2013; Manzini and Mariott 2012). It was demonstrated that increased psychological distance leads to increased chunking of information (Henderson et al. 2006; Wakslak et al. 2006).

People who engage in high-level construals exhibit increased tendency to focus on commonalities or similarities among objects and see the choice set as a set of subgourps of similar items (Förster 2009; Förster et al. 2008; Levy et al. 2002). The stimuli perceived as similar to each other tend to be grouped together as implied by the Gestalt principle (Tversky 1977; Rosch and Mervis 1975). ${ }^{1)}$ The recent works on assortment choice also suggest that individuals who adopt higher-level construals perceive the alternatives in a single assortment as more similar, substitutable, and redundant (Goodman and Malkoc 2012; Henderson 2013; Xu et al. 2013).

One's motivation to categorize the choice set may also depend on the type of choice task. When having to choose a single alternative, one's choice is determined through comparisons of the alternatives by weighing up each alternative's pros and cons (Gensch and Svestka 1979). On the other hand, when making multiple choices simultaneously, choices become dependent on one another (McAlister 1979). Since higherlevel construals take broader perceptual scope, broad bracketing where global consequences of multiple choices are taken into account, becomes more prominent (Read et al. 1999). Thus, in simultaneous multiple choices, consumers adopt options in such a way that minimize the similarities or substitutabilities of the chosen options, in order to maximize the utility totals (McAlister 1979; McAlister and Pessemier 1982; Tversky 1972).

Based on the previous studies, we hypothesize that people adopting higher-level construals are more likely to diversify their choices over a larger number of sub-groups. We further propose that similarity perceptions among the alternatives play an important mediating role in the effect of construal level on categorical variety seeking. Consumers diversifying their choices across subcategories may not be easily observable, especially when categorization of the choice set is not explicit. However, retailers often provide explicit categorization cues such as physical partitioning of goods or explicit category labels.

We first assume that consumers who are

1) Tversky (1977, p. 344) also suggests the bi-directionality between similarity and classification: similarity serves as a basis for the classification of objects, and similarity perception is also affected by the grouping. Thus, whereas similar objects tend to be grouped together, objects grouped together are perceived as more similar (Levy et al., 2002; Mogilner et al., 2008; Rosch and Mervis, 1975; Tversky, 1977). 
motivated to categorize the alternatives will utilize explicit categorization cues if available. However, in the absence of explicit categorical cues, individuals adopting high-level construals will have to resort to their own sub-grouping schemes. By contrast, people with low-level construals tend to search for uniqueness or distinctiveness of each alternative (Henderson 2013; Levy et al. 2002), and would be less motivated to categorize the options even with the presence of explicit categorization cues. Our hypotheses are summarized as follows:

\section{H1: When making multiple choices} simultaneously, people who adopt highlevel (vs. low-level) construals tend to exhibit greater variety seeking across subcategories.

H2: When making multiple choices simultaneously, people who adopt highlevel (vs. low-level) construals choose options whose perceived similarities are lower to one another.

H3: When making a single choice from a choice set (as opposed to making multiple choices), people's motivation for categorization of a choice set is diminished.

$\mathrm{H} 2$ was presented to supplement $\mathrm{H} 1$ by including the case where the explicit partitioning of choice alternatives is not present in purchase situations. Four experiments were designed to test these hypotheses. Study 1 and 2 tried to verify that the subjects with higher-level construals tend to seek greater variety across subcategories (H1). Study 3 tested whether higher level construals elicit greater motivation for subcategorization in the absence of any explicit categorization cues and also tested whether such effects are attenuated when choosing a single alternative (H3). Study 4 was designed to find additional evidence for greater variety seeking at subcategory level for higher construal level when categorization cues are relatively implicit (H1). Study 4 further tested whether high-level construals enhance perceived similarity among within-category options and lowers perceived similarity among chosen options (H2).

\section{Study 1}

The objective of study 1 was to examine the effect of construal level on variety seeking at subcategory level when the alternatives were explicitly partitioned with distinct and easily identifiable categorical labels. The study investigated how people diversify their choices in the context of travel sites selections. The provided travel sites are all located in Jeju Island in South Korea, which is one of the most famous tourist attractions in East Asia. The choice set presented to the subjects was 
composed of forty-eight tourist attractions located within the island.

\subsection{Method}

Ninety undergraduate and graduate students $\left(M_{\text {age }}=22.80,59\right.$ female $)$ were randomly assigned to either of the two construal level conditions (high or low). They were told that the experiment was to investigate their thoughts on travelling. Temporal construal was used to manipulate participants' construal level (Liberman and Trope 1998; Pfeiffer et al. 2014; Song et al. 2014) by asking them to imagine they were planning a sightseeing trip to the Island ${ }^{2)}$ scheduled for either this weekend (low-level construal condition) or next year (high-level construal condition).

Forty-eight tourist attractions in Jeju Island were selected and classified into eight subcategories (e.g., historical sites, museums, islands, monticules, etc.), on reference to the sightseeing information at the official homepage of Jeju Island (www. jeju.go.kr). The participants were asked to choose 6 out of the 48 items, which were explicitly grouped into eight subcategories (see Appendix A). ${ }^{3)}$ They were asked to indicate how far away they perceived the assigned travel timing as a manipulation check. They were also asked to indicate the degree of involvement in the supposed travelling situation through four items (The supposed situation was interesting/meaningful/important to me, and was what I wanted) (Cronbach's $\alpha=.91$ ).

\subsection{Results}

The participants were shown to perceive the trip of next year as more distant than that of this weekend ( $\mathrm{M}=4.52$ vs. $3.26 ; \mathrm{F}(1,88)=$ 35.81, $p<.001)$. They expressed moderately high involvement ( $\mathrm{M}=4.56)$ on that situation, equally for both construal level conditions. The degree to which variety seeking takes place at the subcategory level was measured by the number of subcategories covered by the chosen items (Goukens et al. 2007). The participants in the high-level construal condition ( $\mathrm{M}=5.27)$ diversified their choices across more subcategories than those in the low-level construal condition $(\mathrm{M}=4.80 ; \mathrm{F}(1,88)=8.69, p=.004$; see Figure 1).

2) Jeju Island was selected as a hypothetical travel site because there are a lot of various tourist attractions in Jeju and these items can be grouped into several categories. Well preserved in natural state, Jeju volcanic islands and lava tubes have been listed on the UNESCO's World Natural Heritage since 2007.

3) Participants indicated that the travel items in the choice set were moderately familiar to themselves $(M=3.59)$ and quite typical $(M=5.48)$ for sightseeing in Jeju Island. A high percentage of participants (84.4\%) had experienced travel to Jeju Island and they had been to Jeju Island 1.99 times on average. 
〈Figure 1〉 The Effect of Construal Level on Categorical Variety Seeking (Study 1)

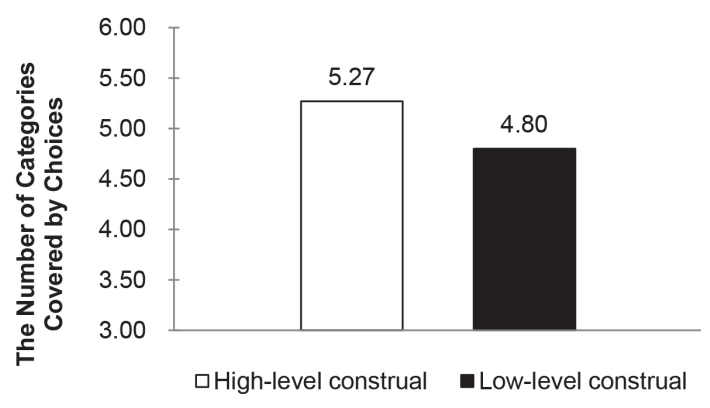

\section{Study 2}

Study 2 was designed to test the same hypothesis as study 1, when categorization cues were less explicit. In the study, the choice set was not explicitly partitioned into several subcategories. Only a literal category label for each alternative was tagged as a categorization cue so that subjects could utilize it if they wanted to. Study 2 examined people's choice in the context of movies selection. Movie genre was used as a category label because genre is one of the most important factors in consumers' choice decisions for movies (e.g., Austin and Gordon 1987; De Silva 1998; Eliashberg and Sawhney 1994).

\subsection{Method}

The authors selected four representative movie genres from hundreds of genres acknowledged worldwide ${ }^{4)}$ : drama, thriller, romance, and action. ${ }^{5)}$ Referring to the film information from the two major Internet portal sites in South Korea, the authors selected 20 popular ${ }^{6)}$ films which had been released since 2000 and could be categorized into four groups according to movie genre (e.g., The Bucket List and I am Sam for the drama genre; The Butterfly Effect and Saw II for the thriller genre; Love Actually and If Only for the romance genre; Mission: Impossible III and The Bourne Ultimatum for the action genre).

Sixty-eight undergraduate students $\left(\mathrm{M}_{\text {age }}=\right.$ 23.03, 28 female) participated in the study. The participants received a booklet titled "Consumer Research on Movies." Then, they were presented with a brief scenario designed for the purpose of manipulating construal levels. The scenario for the low-level construal condition is written as follows: "Imagine that you bought a smart TV recently. For a free gift, you received a movie voucher included on your TV. From now on, you can download and watch 4 movies you

4) http://en.wikipedia.org/wiki/Category:Film_genres

5) Although hybrid movies including more than two genres have emerged recently, referring to the film information from portal sites, the authors treated a first-written genre of each movie as its main genre.

6) Considering that the subjects would be in their twenties, the choice set consisted of popular imported films - most of which are Hollywood films - released from the year of 2000 to 2010. Based on the data of 2013 when study 2 was conducted, the authors chose 20 popular films (five for every genre) which received more than 2000 reviews and got an average rating of higher than 8.0 out of 10.0 . 
choose for a month." As in study 1, temporal construal was used to manipulate construal level. The scenario for the high-level construal condition is different only in the timing of the voucher usage: after six months from now.

The choice set of downloadable movies was presented in a table format (4 columns x 5 rows) where each cell represented a single movie option (see Appendix B). Each movie option entailed its poster ${ }^{7)}$ as well as the information on its title, the release time, and the genre. The choice set was arranged in the layout so that movies of the same genre were not placed next to each other. The main task was to choose four movies they would like to watch at the time when the movies became available. To prevent the participants from excluding the movies they had already watched in their choices, they were allowed to choose to watch again the movies they had already watched. After making their choices, the participants were asked to indicate the perceived temporal distance to the time when the movie download would be available ( 1 = very near, 7 = very far) for manipulation check.

\subsection{Results and Discussions}

The participants in the high-level construal condition perceived the time when the movies became downloadable as farther away ( $\mathrm{M}=$ 5.22) than those in the low-level construal condition $(\mathrm{M}=2.50 ; \mathrm{F}(1,66)=45.98, p<$ .001). Those in the high-level construal condition were shown to diversify their choices over more genres $(\mathrm{M}=2.86)$ than those in the low-level construal condition $(\mathrm{M}=2.34 ; \mathrm{F}(1,66)=$ 10.14, $p<.005$; see Figure 2).

〈Figure 2〉 The Effect of Construal Level on Categorical Variety Seeking (Study 2)

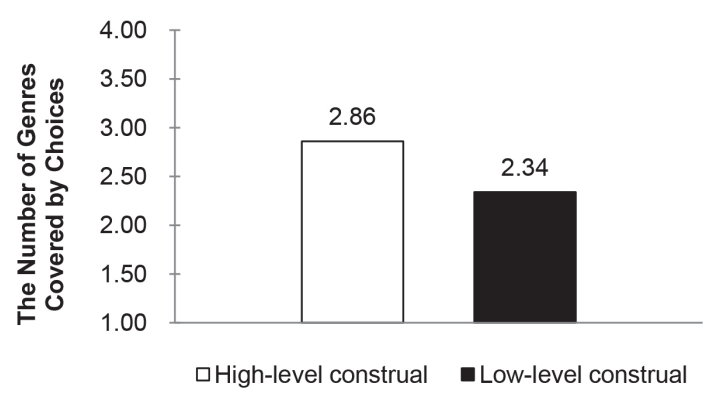

The phenomenon of categorical variety seeking shown in study 1 and 2 can be attributed to the partition dependence effect (Fox et al. 2005), whereby decision makers' subjective and contextual partitioning of the choice set can systematically vary their choices. Fox and his colleagues (2005) investigated the choice distribution phenomenon caused by external setting such as physical partitioning. The current work proposes that greater motivation for categorization induced by higher construal level

7) If given only a title for each movie, people might not properly remember what the movie is about, even though the movie has been popular. Hence, by using movie posters of Korean version which are familiar to Koreans, it was expected that participants could remind of movies more immediately. 
would lead people to using explicit categorization cues more readily. The next study, study 3 , was designed to test more directly whether construal level moderates one's motivation to categorize alternatives without any explicit subgrouping cues. Study 3 also demonstrated that the increased motivation to categorize alternatives for high-level construal is attenuated in a single choice task whereby the subjects have to choose only one alternative.

\section{Study 3}

Study 3 tried to test Hypothesis 1 employing the movies selection context again while excluding the explicit genre information. Study 3 also tested whether the greater motivation for subcategorizing the choice set for higher construals is valid for a single choice task. Construal level was manipulated by asking participants to describe either "why" or "how" a target person performed an action (Liberman et al. 2007).

\subsection{Method}

One hundred and forty-six undergraduate students $\left(\mathrm{M}_{\text {age }}=23.18\right.$, 62 female $)$ participated in the experiment for course credit. This study employed a 2(construal level: high vs. low) $\mathrm{x}$ 2(choice task: multiple choices task vs. single choice task) between-subjects experiment design. Each participant received a questionnaire composed of two parts, where the first part was designed for construal level manipulation. In the first part of the questionnaire entitled "Construction of Narratives," the subjects were asked to describe either "why" (i.e., high-level construal) or "how" (i.e., low-level construal) a target person performed a certain action. For example, "Chris is considering opening a bank account. Please try to imagine the situation and write down why (how) Chris is doing it" (Liberman et al. 2007; Stephan et al. 2011). The other actions described in this part include looking for a book in the library, enrolling in a fitness program, subscribing to a newspaper, learning to play the piano, buying a laptop.

In the second part, the participants were provided with a scenario of movie choice just like in study 2, but without temporal distance variation. The short scenario for all experimental conditions was as follows: "Imagine that you bought a monitor recently and received a movie voucher for a free gift. You can download and watch 4 movies at anytime." The choice set of 16 downloadable movies was presented. ${ }^{8)}$ Each movie option entailed its poster as well as information on its title and the release year. However, the labels of movie genre were

8) Study 3 reduced the number of movies in the choice set from 20(study 2) to 16 because some participants from study 2 mentioned that the set of movie posters were overwhelming to look through in a single page. 
excluded so that the participants could not be easily directed to categorize the alternatives utilizing explicit cues (e.g., movie genre). ${ }^{9)}$

The main task was to choose either 4 movies simultaneously (multiple choices task) or only one movie (single choice task) they would like to watch. The participants were allowed to choose movies that they had already watched. After making their choices, they were asked to indicate how much effort they put into categorization of the choice set before determining their final selection $(1=$ not at all, $7=$ very much). Only those in the multiple choices task were asked to rate how much attention they paid to the similarities among the films. The participants indicated how much they were familiar with the given movies in general $(1=$ not at all, $7=$ very much), which was to confirm they were knowledgeable enough to set their own criterion for categorization.

\subsection{Results and Discussions}

The participants indicated that they were familiar with the presented movies in general $(\mathrm{M}=5.83, \mathrm{SD}=1.29)$. A 2(construal level: high versus low) x 2 (choice task: multiple choices task versus single choice) ANOVA results indicate that the main effect of choice task on categorical variety seeking is significant $(F(1,142)=4.19, p<.05)$, while the effect of construal level is not significant $(\mathrm{F}(1,142)=$ 1.31, $p>$.25). The interaction effect between the two factors is marginally significant $(F(1,142)$ $=2.98, p<.09$; see Figure 3). As predicted, those in the multiple choices task were more motivated to categorize the films when they adopted high-level construals $(\mathrm{M}=4.77)$ than when they adopted low-level construals $(\mathrm{M}=3.91 ; \mathrm{t}(67)=2.00, p<.05)$. The participants in the single choice task were low

〈Figure 3〉 The Effects of Construal Level and Motivation for Categorization on Categorical Variety Seeking in Multiple vs. Single Choice Tasks (Study 3)

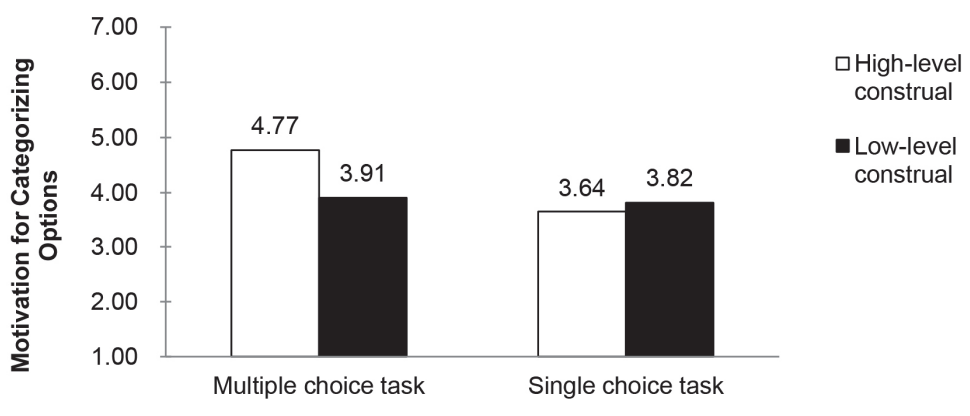

9) Unlike study 2, the degree of variety seeking at category level was not analyzed because movie genre was no more explicit categorization cue in study 3 . 
in their motivation for categorization scores regardless of their construal level $\left(\mathrm{M}_{\text {high }}=\right.$ 3.64, $\left.\mathrm{M}_{\mathrm{low}}=3.82 ; \mathrm{t}(75)=.04, p>.67\right)$. People adopting higher-level construals exhibited greater motivation for categorization even without an explicit categorization cue and such effects were diminished in a single choice task. In the multiple choices task, an additional analysis was done to see if people adopting high-level construals pay more attention to the similarities between the options than those adopting low-level construals. The difference was not statistically significant $\left(\mathrm{M}_{\text {high }}=4.29, \mathrm{M}_{\mathrm{low}}=\right.$ $3.65, \mathrm{~F}(1,67)=1.78, p=.19)$.

\section{Study 4}

Study 4 was designed to investigate the role of perceived similarities between the alternatives on categorical variety seeking. The participants were asked to rate the perceived similarities between every pair of the options, i.e., both the within-category pairs and between-category pairs. The similarity scores of both within- and between-category pairs were compared between high- and low-level construal conditions. It was expected that the subjects adopting higherlevel construals would perceive the withincategory pairs as more similar to each other than those adopting low-level construals.

In categorization process, those with higher- level construals were expected to focus more on the between-category differences than the within category differences. Those with lowerlevel construals would focus more on the distinctiveness of every option with less attention on the categorical differences. In study 4 , construal levels were manipulated by words generation methods (Fujita et al. 2006; Henderson 2013; Kyung et al. 2014). High-level (low-level) construal was elicited by asking the subjects to generate superordinate category labels (subordinate examples) for the given words.

\subsection{Method}

Sixty-two undergraduate and graduate students $\left(\mathrm{M}_{\text {age }}=24.4 ; 25\right.$ female $)$ participated in the study. The between-subjects experimental design contained high- and low-level construal conditions. The participants were randomly assigned to either of the two conditions and were asked to rate the perceived similarity of every option pair in the choice set. The six alternatives were presented in a way that they could be grouped into two superordinate categories based subtle but explicit cues. The variety seeking at category level was determined by whether a subject chose two options from different categories or from the same category.

At the beginning of the experiment, the participants received a booklet titled "A Study on the Relationship between Linguistic Capabilities and Food Preferences." The first task was 
conducted to induce either high- or low-level construal. The participants in the high-level construal condition ( $\mathrm{n}=31$ ) were asked to generate superordinate category labels for 15 common objects given (e.g., music, automobiles, vegetables), whereas those in the low-level construal condition $(\mathrm{n}=31)$ were asked to generate at least three specific examples for the same objects.

The participants were presented with a set of general dining options (see Appendix C). The choice set was organized with six popular dishes in South Korea: 3 Korean dishes (i.e., soybean paste stew, kimchi stew, and beef-bone soup) and 3 Chinese dishes (i.e., black-beansauce noodles, spicy seafood soup, and noodles in chicken broth). To make the categorization cue explicit, but subtle, Korean dishes and Chinese dishes were presented simultaneously but separated into two different rows. The participants were asked to choose only two dining menus they preferred for their dinner right after completing the experiment. ${ }^{10)}$ However, to prevent them from considering match or mismatch of their chosen pair, they were asked to rank the two most preferred options, rather than to choose two options. Then, they were asked to indicate perceived similarity on a seven-point scale ( 1 = totally different, $7=$ very similar) for every possible pair within the choice set. The similarity scores for the 6 within-category pairs were averaged to form a within-category pair similarity index and the scores for the 9 between-category pairs were averaged to generate a between-category pair similarity index. The similarity score of each participant's chosen pair was recorded separately, regardless if the pair was a within- or a between-category pair.

\subsection{Results and Discussions}

Supporting our hypothesis, a greater percentage of the subjects chose options from different categories in the high-level construal condition than in the low-level construal condition. 74\% of the subjects covered both of two categories in the high-level construal condition compared with $45 \%$ in the low-level construal condition $\left(x^{2}=5.429, p=.020\right.$; see Figure 4). Study 4 also revealed that higher-level construals lead individuals to more categorical variety.

〈Figure 4〉 The Effect of Construal Level on Categorical Variety Seeking (Study 4)

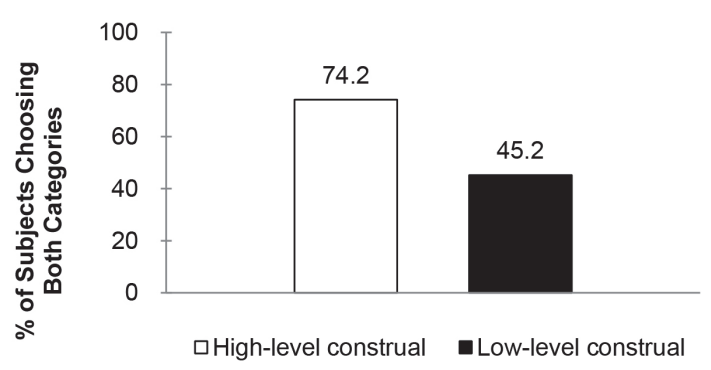

10) Study 4 was conducted between five and six p.m. before all the participants had dinner. 
As shown in Figure 5, an ANOVA on between-category pair similarity yielded no main effect of construal level $\left(\mathrm{M}_{\text {high }}=2.61\right.$ vs. $\left.\mathrm{M}_{\text {low }}=2.39 ; \mathrm{F}(1,60)=1.886, p=.175\right)$. However, the within-category pair similarity was significantly higher in high-level construal than low-level construal $\left(\mathrm{M}_{\text {high }}=4.47\right.$ vs. $\mathrm{M}_{\text {low }}$ $=3.80 ; \mathrm{F}(1,60)=6.945, p=.011)$. Moreover, perceived similarity score for the chosen pair was significantly lower in the high-level construal condition than in the low-level construal condition $\left(\mathrm{M}_{\text {high }}=3.10\right.$ vs. $M_{\text {low }}=4.06 ; \mathrm{F}(1,60)=$ 4.989, $p=.029$ ), supporting H2.

The perceived similarity between options from two different categories in high construal condition was as low as that in low construal condition. In contrast, the subjects engaged in high-level construals perceived within-category pairs as more similar as those who engaged in low-level construals. Moreover, higher-level construals led the subjects to choosing options less similar to each other. Even though the subjects with low-level construals perceived between-category differences, they seem to have ignored the differences because their motivation for categorization is low.

\section{Conclusion}

Based on the fact that variety seeking behavior can take place not only at brand level but also at category or subcategory level, this study tried to identify the factors determining the level at which variety seeking takes place. Consumers' construal level was proposed as a crucial variable in this context. Four experiments were designed to examine the role of construal level on subcategorization of choice set and variety seeking at subcategory level.

Study 1 showed that subjects adopting higherlevel construals tend to seek more variety at (sub)category level, under explicit categorization with distinctive category labels. Study 2 replicated study 1 in the movies selection context where

〈Figure 5〉 The Effect of Construal Level on Perceived Similarity Ratings for Option Pairs (Study 4)

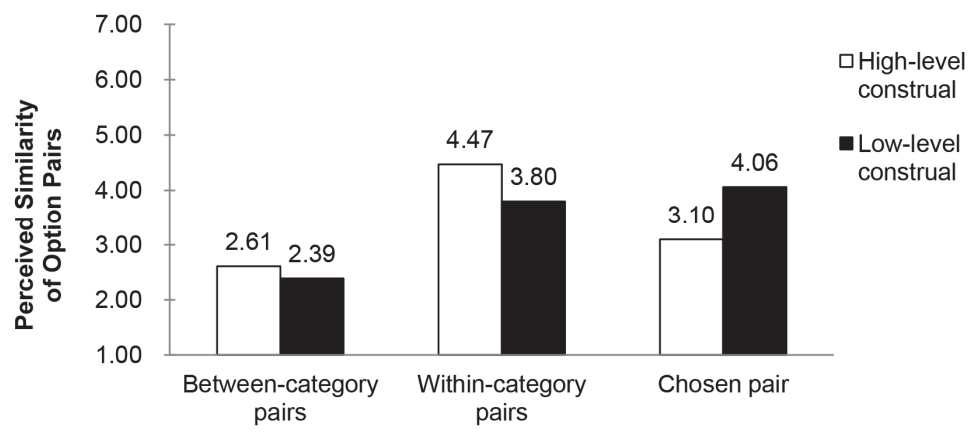


the subjects were provided with literal category labels as explicit categorization cues. Study 3 demonstrated that higher construal levels elicit consumers' greater motivation to categorize the choice set without explicit categorization cues. Study 4 provided an additional evidence for greater variety seeking at category level for individuals with higher-level construals and showed the role of similarity perception in categorization and variety seeking. The subjects adopting higher-level construals perceived withincategory options as more similar and they chose less similar options, resulting in higher level variety seeking.

When having to choose only a single alternative, people only need to adopt the best option based on their preference in a piecemeal way. However, this study indicates that higher-level construals can alter one's choice pattern by eliciting reorganization of the alternatives, assuming that one's default mental representation is low-level (Khan et al. 2011). Suppose that there is a person who usually prefers playing tennis or playing basketball to going to art exhibitions in the spare time. According to the findings of the study, if one must choose only two activities from the three, high-level construals would lead him or her to choosing one of two sports games and art exhibition.

The demonstrated choice patterns violate the basic principles of rational choice whereby choices can be explained solely by the preferences for individual options (Bell et al. 1975; Luce
1959). The results of the study imply that as consumers' construal level gets higher, the gap in choice probabilities between the most and the second most preferred options in each category can become larger (Nedungadi 1990) by highlighting the most representative and preferred brand in each (sub)category compared to the second one. Such a phenomenon indicates that the IIA principle (Luce 1959) can be violated even without introduction of new alternatives into the choice set (Huber et al. 1982). In devising effective marketing strategies, marketers should not only understand people's preference for their brands, but also their mental representation and the construal level as to the decision problem.

The current study is limited in that it only investigated consumers' distributing their choices across subcategories within basically the same product category. A follow-up study on whether variety seeking can actually be pursued across completely different product categories for those individuals with an even higher construal level will be needed. In this regard, this study provides important implications for the future research direction. Because one's construal level and thus perceived substitutabilities among various product categories may be quite idiosyncratic, his or her actual choices can be very unpredictable. For example, one's ice cream choices can be supplemented by not only other ice cream choices, but also by other snacks, movies, games or anything that can give pleasure. This also 
illustrates the limitations of traditional utilitybased choice studies. To overcome these limitations and understand consumers' actual choice thoroughly, research should be conducted to measure the similarities or substitutabilities among all categories of consumer goods and relate them to how they distribute their choices across the least similar categories.

〈Received August 31. 2018〉

〈Accepted July 18. 2019〉

\section{References}

Austin, Bruce A. and Thomas F. Gordon (1987), "Movie Genres: Toward a Conceptualized Model and Standardized Definitions," in Current Research in Film: Audiences, Economics and Law: Vol. 3 (ed. by B.A. Austin). Ablex Publishing Corporation: Norwood, NJ.

Bar-Anan, Yoav, Nira Liberman, and Yaacov Trope (2006), "The Association between Psychological Distance and Construal Level: an Implicit Association Test," Journal of Experimental Psychology: General, 135(4), 609-622.

Barsalou, Lawrence W. (1983), “Ad Hoc Categories," Memory and Cognition, 11(3), 211-227.

Bell, David E., Ralph L. Keeney, and John D. C. Little (1975), "A Market Share Theorem,"
Journal of Marketing Research, 12(2), 136-141.

De Silva, I. (1998), "Consumer Selection of Motion Pictures," in The Motion Picture Mega Industry (ed. by B.R. Litman), Allyn and Bacon Publishing Inc., Boston, MA.

Eliashberg, Jehoshua and Mohanbir S. Sawhney (1994), "Modeling Goes to Hollywood: Predicting Individual Differences in Movie Enjoyment," Management Science, 40(9), 1151-1173.

Förster, Jens (2009), "Relations between Perceptual and Conceptual Scope: How Global versus Local Processing Fits a Focus on Similarity versus Dissimilarity," Journal of Experimental Psychology: General, 138(1), 88-111.

Förster, Jens, Nira Liberman, and Stefanie Kuschel (2008), "The Effect of Global versus Local Processing Styles on Assimilation versus Contrast in Social Judgment," Journal of Personality and Social Psychology, 94 (4), 579-599.

Fox, Craig R., Rebecca K. Ratner, and Daniel S. Lieb (2005), "How Subjective Grouping of Options Influences Choice and Allocation: Diversification Bias and the Phenomenon of Partition Dependence," Journal of Experimental Psychology: General, 134(4), 538-551.

Fujita, Kentaro, Yaacov Trope, Nira Liberman, and Maya Levin-Sagi (2006), "Construal Levels and Self-Control," Journal of 
Personality and Social Psychology, 90(3), 351-367.

Fukukura, Jun, Melissa J. Ferguson, and Kentaro Fujita (2013), "Psychological Distance Can Improve Decision Making under Information Overload via Gist Memory," Journal of Experimental Psychology: General, 142(3), 658-665.

Gensch, Dennis H. and Joseph A. Svestka (1979), “An Exact Hierarchical Algorithm for Determining Aggregate Statistics from Individual Choice Data," Management Science, 25(10), 939-952.

Givon, Moshe (1984), "Variety Seeking through Brand Switching," Marketing Science, 3 (1), 1-22.

Goodman, Joseph K. and Selin A. Malkoc (2012), "Choosing for Here and Now vs. There and Later: the Moderating Role of Psychological Distance on Assortment Size Preferences," Journal of Consumer Research, 39(4), 751-768.

Goukens, Caroline, Siegfried Dewitte, Mario Pandelaere, and Luk Warlop (2007), Wanting a Bit(e) of Everything: Extending the Valuation Effect to Variety Seeking," Journal of Consumer Research, 34(3), 386394.

Han, Sangman and Yongsik Nam (1997), "A Comparative Study of Choice-Set Formation through Variety-Seeking in Consumer Behavior," Journal of Korean Marketing Association, 12(June), 49-76.
Henderson, Marlone D. (2013), "When Seeing the Forest Reduces the Need for Trees: the Role of Construal Level in Attraction to Choice," Journal of Experimental Social Psychology, 49(4), 676-683.

Henderson, Marlone D., Kentaro Fujita, Yaacov Trope, and Nira Liberman (2006), "Transcending the "Here": the Effect of Spatial Distance on Social Judgment," Journal of Personality and Social Psychology, 91 (5), 845-856.

Huber, Joel, John W. Payne, and Christopher Puto (1982), "Adding Asymmetrically Dominated Alternatives: Violatons of Regularity and Similarity Hypothesis," Journal of Consumer Research, 9(June), 90-98.

Khan, Uzma, Meng Zhu, and Ajay Kalra (2011), "When Trade-Offs Matter: the Effect of Choice Construal on Context Effects," Journal of Marketing Research, 48(1), 62-71.

Kyung, Ellie J., Geeta Menon, and Yaacov Trope (2014), "Construal Level and Temporal Judgments of the Past: the Moderating Role of Knowledge," Psychonomic Bulletin \& Review, 21(3), 734-739.

Labroo, Aparna A. and Vanessa M. Patrick (2009), "Psychological Distancing: Why Happiness Helps You See the Big Picture," Journal of Consumer Research, 35(5), 800-809.

Levy, Sheri.R., Antonio L. Freitas, and Peter Salovey (2002), "Construing Action Abstractly 
and Blurring Social Distinctions: Implications for Perceiving Homogeneity among, but also Empathizing with and Helping, Others," Journal of Personality and Social Psychology, 83(5), 1224-1238.

Liberman, Nira, Michael D. Sagristano, and Yaacov Trope (2002), "The Effect of Temporal Distance on Level of Construal," Journal of Experimental Social Psychology, 38(6), 523-535.

Liberman, Nira and Yaacov Trope (1998), "The Role of Feasibility and Desirability Considerations in Near and Distant Future Decisions: a Test of Temporal Construal Theory," Journal of Personality and Social Psychology, 75(1), 5-18.

Liberman, Nira, Yaacov Trope, Sean M. McCrea, and Steven J. Sherman (2007), "The Effect of Level of Construal on the Temporal Distance of Activity Enactment," Journal of Experimental Social Psychology, 43(1), 143-149.

Luce, R. Duncan (1959), Individual Choice Behavior: A Theorem Analysis. Wiley, NY. Manzini, Paola and Marco Mariotti (2012), "Categorize then Choose: Boundedly Rational Choice and Welfare," Journal of the European Economic Association, 10(5), 1141-1165.

Marguc, Janina, Jens Förster, and Gerban A. Van Kleef (2011), “Stepping Back to See the Big Picture: When Obstacles Elicit Global Processing," Journal of Personality and Social Psychology, 101(5), 883-901.
McAlister, Leigh (1979), "Choosing Multiple Items from a Product Class," Journal of Consumer Research, 7(3), 213-224.

Mogilner, Cassi, Tamar Rudnick, and Sheena S. Iyengar (2008), "The Mere Categorization Effect: How the Presence of Categories Increases Choosers' Perceptions of Assortment Variety and Outcome Satisfaction," Journal of Consumer Research, 35(2), 202-215.

Nedungadi, Prakash (1990), "Recall and Consumer Consideration Sets: Influencing Choice without Altering Brand Evaluations," Journal of Consumer Research, 17(3), 263-276.

Pfeiffer, Bruce E., Helen Deval, Frank R. Kardes, Douglas R. Ewing, Xiaoqi Han, and Maria L. Cronley (2014), "Effects of Construal Level on Omission Detection and Multiattribute Evaluation," Psychology and Marketing, 31(11), 992-1007.

Read, Daniel and George Loewenstein (1995), "Diversification Bias: Explaining the Discrepancy in Variety-Seeking between Combined and Separated Choices," Journal of Experimental Psychology: Applied, 1(1), 34-49.

Read, Daniel, George Loewenstein, and Matthew Rabin (1999), “Choice Bracketing," Journal of Risk and Uncertainty, 19(1), 171-197. Rosch, Eleanor and Carolyn B. Mervis (1975), "Family Resemblances: Studies in the Internal Structure of Categories," Cognitive Psychology, 7(4), 573-605.

Rosch, Eleanor, Carolyn B. Mervis, Wayne D. 
Gray, David M. Johnson, and Penny Boyes-Braem (1976), "Basic Objects in Natural Categories," Cognitive Psychology, 8(3), 382-439.

Simonson, Itamar (1990), "The Effect of Purchase Quantity and Timing on Variety-Seeking Behavior," Journal of Marketing Research, 27(2), 150-162.

Song, Tae Ho, Mincheol Kim, and Wooli Ko (2014), "The Application of the GoalGradient Hypothesis and the Temporal Construal Theory to Customer Loyalty Programs: Goal Gradient Hypothesis and Temporal Construal Theory," Asia Marketing Journal, 16(1), 1-12.

Stephan, Elena, Nira Liberman, and Yaacov Trope (2011), "The Effects of Time Perspective and Level of Construal on Social Distance," Journal of Experimental Social Psychology, 47(2), 397-402.

Trope, Yaacov and Nira Liberman (2003), “Temporal Construal," Psychological Review, 110(3), 403-421.

Trope, Yaacov and Nira Liberman (2010), "Construal-Level Theory of Psychological Distance," Psychological Review, 117(2), 440-463.
Trope, Yaacov, Nira Liberman, and Cheryl J. Wakslak (2007), “Construal Levels and Psychological Distance: Effects on Representation, Prediction, Evaluation, and Behavior," Journal of Consumer Psychology, 17(2), 83-95.

Tversky, Amos (1972), "Elimination by Aspects: a Theory of Choice," Psychological Review, 79(4), 281-299.

Tversky, Amos (1977), "Features of Similarity," Psychological Review, 84(4), 327-352.

$\mathrm{Xu}$, Jing, Zixi Jiang, and Ravi Dhar (2013), "Mental Representation and Perceived Similarity: How Abstract Mindset Aids Choice from Large Assortments," Journal of Marketing Research, 50(4), 548-559.

Wakslak, Cheryl J., Yaacov Trope, Nira Liberman, and Rotem Alony (2006), "Seeing the Forest When Entry is Unlikely: Probability and the Mental Representation of Events," Journal of Experimental Psychology: General, 135(4), 641-653.

Yoon, Song-Oh and Kwanho Suk (2013), "The Influence of Household Properties on Simultaneous Variety Seeking," Journal of Korean Marketing Association, 28(August), 153-169. 


\section{〈Appendices〉}

Appendix A. The Choice Set of Travel Items in Study 1

\begin{tabular}{|c|c|c|}
\hline Category & Items & Check(O) \\
\hline \multirow{4}{*}{$\begin{array}{c}\text { Historical } \\
\text { Sites }\end{array}$} & $\begin{array}{c}\text { Kim Man-deok } \\
\text { Memorial Hall }\end{array}$ & \\
\cline { 2 - 3 } & Gwandeokjeong & \\
\cline { 2 - 3 } & Chusa Exile Site & \\
\cline { 2 - 3 } & Jeju Hyanggyo & \\
\cline { 2 - 3 } & Samseonghyeol & \\
\cline { 2 - 3 } & Seongeup Folk Village & \\
\hline
\end{tabular}

\begin{tabular}{|c|c|c|}
\hline Category & Items & Check (O) \\
\hline \multirow{4}{*}{ Monticules } & Seongsan Ilchulbong & \\
& Mt. Songaksan & \\
\cline { 2 - 3 } & Mt. Sanbangsan & \\
\cline { 2 - 3 } & Ddarabi Oreum & \\
\cline { 2 - 3 } & Abu Oreum & \\
\cline { 2 - 3 } & Geomi Oreum & \\
\hline
\end{tabular}

\begin{tabular}{|c|c|c|}
\hline \multirow{4}{*}{ Caves \& } & Sangumburi & \\
\cline { 2 - 3 } Waterfalls & Manjang Cave & \\
\cline { 2 - 3 } & Ssangyong Cave & \\
\cline { 2 - 3 } & Jeongbang & \\
& Waterfall & \\
\cline { 2 - 3 } & Cheonjiyeon & \\
& Waterfall & \\
\hline & Eongddo Waterfall & \\
\hline
\end{tabular}

\begin{tabular}{|c|c|c|}
\hline \multirow{4}{*}{ Botanic } & Hallim Park & \\
\cline { 2 - 3 } Gardens & Bijarim Forest & \\
\cline { 2 - 3 } & Wildflower Garden & \\
\cline { 2 - 3 } & Yeomiji & \\
& Bortanic Garden & \\
\cline { 2 - 3 } & Jeolmul Natural & \\
& Recreation Forest & \\
\cline { 2 - 3 } & Halla Arboretum & \\
\hline
\end{tabular}

\begin{tabular}{|c|c|c|}
\hline \multirow{4}{*}{$\begin{array}{c}\text { Coastal } \\
\text { Topography }\end{array}$} & Yongduam & \\
\cline { 2 - 3 } & Columnar Joint & \\
\cline { 2 - 3 } & Oedolgae & \\
\cline { 2 - 3 } & Suwolbong Peak & \\
\cline { 2 - 3 } & Seopjikoji & \\
\cline { 2 - 3 } & Yongmeori Coast & \\
\hline
\end{tabular}

\begin{tabular}{|c|c|c|}
\hline \multirow{4}{*}{ Islands } & Mara Island & \\
\cline { 2 - 3 } & Chagwi Island & \\
\cline { 2 - 3 } & Udo Island & \\
\cline { 2 - 3 } & Beomseom Island & \\
\cline { 2 - 3 } & Biyang Island & \\
\cline { 2 - 3 } & Gapa Island & \\
\hline
\end{tabular}

\begin{tabular}{|c|c|c|}
\hline \multirow{4}{*}{ Museums } & $\begin{array}{c}\text { Jeju Natural History } \\
\text { Museum }\end{array}$ & \\
\cline { 2 - 3 } & $\begin{array}{c}\text { Lee Jung-seop } \\
\text { Museum }\end{array}$ & \\
\cline { 2 - 3 } & $\begin{array}{c}\text { Dackjongie } \\
\text { Art Gallery }\end{array}$ & \\
\cline { 2 - 3 } & Citrus Museum & \\
\cline { 2 - 3 } & Teddy Bear Museum & \\
\cline { 2 - 3 } & Osulloc Tea Museum & \\
\hline
\end{tabular}

\begin{tabular}{|c|c|c|}
\hline \multirow{4}{*}{ Theme } & $\begin{array}{c}\text { Gimnyoung } \\
\text { Maze Park }\end{array}$ & \\
\cline { 2 - 3 } Parks & $\begin{array}{c}\text { Soingook } \\
\text { Themepark }\end{array}$ & \\
\cline { 2 - 3 } & $\begin{array}{c}\text { Jeju Racecourse } \\
\text { Park }\end{array}$ & \\
\cline { 2 - 3 } & Pacific Land & \\
\cline { 2 - 3 } & Jeju Stone Village & \\
\cline { 2 - 3 } & Jeju Sculpture Park & \\
\hline
\end{tabular}


Appendix B. The Choice Set of Movies in Study 2

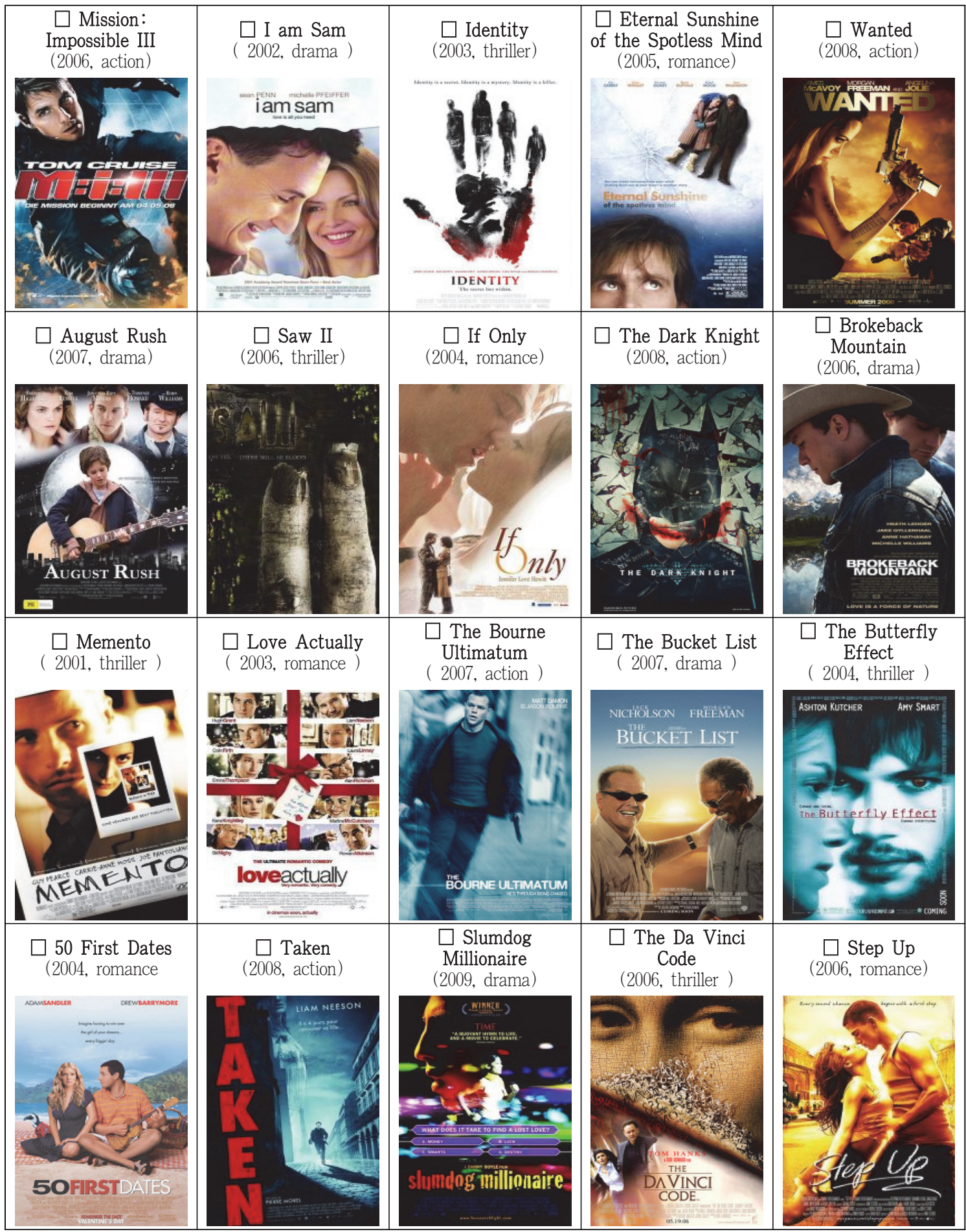

The Effect of Construal Level on Variety Seeking across Subcategories 19 
Appendix C. The Choice Set of Dining Menus in Study 4

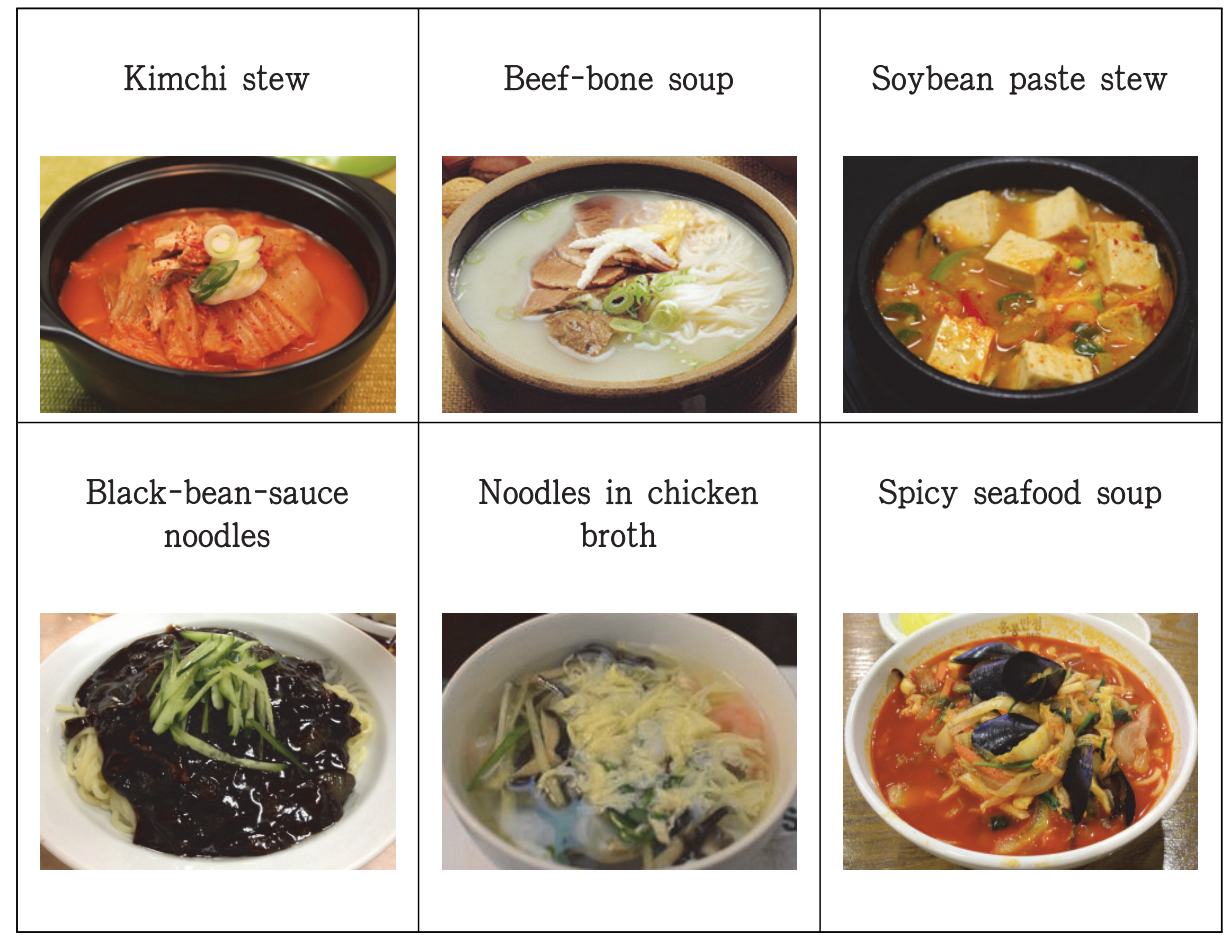

Rank two top-preferred options below.

Rank 1:

Rank 2: 